\title{
PENENTUAN KADAR LUNACRIDINE PADA EKSTRAK KAYU SANREGO (Lunasia amara Blanco) YANG DIEKSTRAKSI DENGAN METODE MASERASI DAN REFLUKS
}

\author{
Rugayyah Alyidrus
}

\author{
Sekolah Tinggi Ilmu Kesehatan Mega Rezky Makassar \\ Email : rugayyahalyidrus@ymail.com
}

\begin{abstract}
Determination of the research done on the extract lunacridine Sanrego $(\underline{L}$. amara Blanco) in extraction with various methods of extraction. This study aims to determine the various menthods of extraction (maceration, refluks and soxhletasi) are most appropriate to extractim sanrego lunacridine on wood extract (L. amara Blanco) and determine the levels with TLC-Densitometry. Wood sanrego (L.amara Blanco) extrac dusing methanol solvent. Lunacridine as marker and sample in TLC and eluted wiyh the eluent $n$-hexane:ethyl acetate (2:8) and then scanned with a TLC-Densitometry of wavelength $303 \mathrm{~nm}$. The results showed that the most appropriate extraction method is refluks with quote lunacridine content 37,52 $\mu \mathrm{g} / \mu \mathrm{L}$ that in maceration 35,03 $\mu \mathrm{g} / \mu \mathrm{L}$.
\end{abstract}

Keywords: Lunacridine, wood sandrego (L. amara Blanco), maceration, reflux, TLCdensitometry.

\section{PENDAHULUAN}

Pemanfaatan obat tradisional di Indonesia saat ini sudah cukup luas. Pengobatan tradisional ini terus dikembangkan dan dipelihara sebagai warisan budaya bangsa yang terus ditingkatkan melalui penggalian penelitian, pengujian dan pengembangan serta penemuan obatobatan dengan pendekatan ilmu pengetahuan dan teknologi. ${ }^{1}$

Salah satu tumbuhan yang mempunyai khasiat sebagai obat adalah Sanrego (L. amara Blanco).
Ludavina S. De Parua (1978) yang melaporkan bahwa kayu tumbuhan ini mengandung alkaloid lunacridine, lunasine, dan lunanine. ${ }^{2}$

Alkaloid Kayu Sanrego (L. amara Blanco) memiliki rumus empiris $\mathrm{C}_{17} \mathrm{H}_{23} \mathrm{NO}_{4}$ dan mengandung dua kelompok metoksil, satu gugus $\mathrm{N}$-metil dan dua atom hidrogen aktif serta merupakan alkaloid quinolin, dimana mempunyai 2 cincin karbon dengan 1 atom nitrogen yang berlimpah di Rutaceae. Lunacridine pada kayu 
Penentuan kadar lunacridine pada ekstrak Kayu Sanrego (Lunasia amara Blanco) yang diekstraksi dengan metode Maserasi dan Refluks.

Sanrego (L. amara Blanco) adalah alkaloid quinolin sebagai antikanker. ${ }^{3}$

Berdasarkan hal tersebut diatas, maka akan dilakukan penelitian penentuan kadar senyawa lunacridine pada kayu Sanrego (L. amara Blanco) dengan menggunakan dua metode ekstraksi sehingga menambah data ilmiah tanaman obat.

\section{METODE PENELITIAN}

Jenis Penelitian

Jenis penelitian ini dilakukan secara observasi, yang merupakan skala laboratorium.

\section{Alat Dan Bahan}

Alat yang digunakan Batang pengaduk, cawan porselin, chamber (Camag), corong kaca (Pyrex), eksikator (Memmert), gelas kimia (Pyrex), gelas ukur (Pyrex), labu ukur (Pyrex), lampu UV 254 nm dan 366 $\mathrm{nm}$, mikropipet (Camag), pipa kapiler, sendok tanduk, seperangkat alat KLTDensitometri (Camag), seperangkat alat maserasi, seperangkat alat refluks, seperangkat alat rotavapor $\left(\| k a^{\circledR}\right)$, timbangan analitik (Chyo) dan vial.

Bahan yang digunakan Air suling, aluminium foil, etil asetat, kayu Sanrego (L. amara Blanco), kertas saring, lempeng KLT (E.Merck) , metanol, n-heksan, pembanding lunacridine dan slika gel.

\section{Prosedur Kerja}

\section{Penyiapan alat dan bahan}

Alat dan bahan disiapkan sesuai dengan kebutuhan penelitian yang akan dilakukan.

\section{Pengolahan sampel}

Sampel dibersihkan kemudian dipotong kecil-kecil setelah itu dikeringkan.

\section{Ekstraksi sampel}

\section{Maserasi}

Simplisia kayu Sanrego ( $L$. amara Blanco) ditimbang sebanyak 150 gram dimasukkan ke dalam wadah maserasi, ditambahkan metanol sebanyak $1000 \mathrm{~mL}$, dibiarkan selama 5 hari dalam bejana tertutup dan terlindung dari cahaya sambil berulang-ulang diaduk. Setelah 5 hari simplisia di saring. Hal ini dilakukan sebanyak 3 kali. Hasil penyarian yang didapat kemudian dikumpulkan dan diuapkan dengan menggunakan rotavapor dan diperoleh ekstrak metanol pekat sebanyak 3,67 gram dan dilakukan pengujian selanjutnya.

\section{Refluks}

Simplisia kayu Sanrego (L. amara Blanco) ditimbang sebanyak 150 gram diekstraksi secara refluks dengan pelarut metanol sebanyak 500 $\mathrm{mL}$ selama 4 jam. Setelah itu disaring. Hasil ekstraksi diuapkan menggunakan rotavapor hingga 
Penentuan kadar lunacridine pada ekstrak Kayu Sanrego (Lunasia amara Blanco) yang diekstraksi dengan metode Maserasi dan Refluks.

didapatkan ekstrak kental sebanyak

5,27 gram dan dilakukan pengujian selanjutnya.

Identifikasi Lunacridine

Masing-masing ekstrak metanol kayu Sanrego (L. amara Blanco) dari maserasi dan refluks serta pembanding lunacridine dilarutkan dengan metanol kemudian ditotol pada lempeng KLT. Dimasukkan ke dalam chamber eluen $n$-heksan : etil asetat $(2$ : 8). Diamati pada sinar UV $254 \mathrm{~nm}$, sinar UV 366 nm. Bercak yang diperoleh diamati dan dihitung nilai Rfnya. Kedua metode dibandingkan dengan lunacridine jika noda, warna dan nilai Rf-nya sama dan sejajar berarti sampel tersebut mengandung lunacridine.

\section{KLT-Densitometri}

Disiapkan lempeng KLT dengan ukuran $10 \times 13 \mathrm{~cm}$. Dibuat larutan baku dengan cara pembanding lunacridine ditimbang sebanyak 5 mg dimasukkan dalam labu ukur $5 \mathrm{~mL}$ kemudian dilarutkan dengan metanol hingga tanda batas dan homogenkan. Dari larutan baku tersebut dibuat empat konsentrasi masing-masing 20 ppm, 40 ppm, 60 ppm dan 80 ppm. Pada sampel masing-masing metode ekstraksi ditimbang $5 \mathrm{mg}$ dan dilarutkan dengan metanol. Masingmasing konsentrasi ditotolkan dengan menggunakan mikropipet sebanyak 1 $\mu \mathrm{L}$ Kemudian masing-masing metode ekstraksi pada sampel ditotol juga pada lempeng KLT, lalu di elusi dengan n-heksan : etil asetat (2 :8). Noda yang terpisah diamati dengan lampu UV $254 \mathrm{~nm}$ dan diukur dengan KLT-Densitometri pada panjang gelombang maksimum $303 \mathrm{~nm}$. Dilakukan analisis terhadap hasil scan.

\section{HASIL PENELITIAN}

Tabel 1. JumLah ekstrak yang diperoleh dari kayu sanrego (L. amara Blanco).

\begin{tabular}{ccccc}
\hline No & Metode ekstraksi & Berat sampel $(\mathbf{g})$ & $\begin{array}{c}\text { Cairan penyari } \\
(\mathbf{m L})\end{array}$ & $\begin{array}{c}\text { Ekstrak kering } \\
(\mathbf{g})\end{array}$ \\
\hline 1 & Maserasi & 150 & 3000 & 3,67 \\
2 & Refluks & 150 & 1500 & 5,27 \\
\hline
\end{tabular}


Penentuan kadar lunacridine pada ekstrak Kayu Sanrego (Lunasia amara Blanco) yang diekstraksi dengan metode Maserasi dan Refluks.

Tabel 2. Hasil perhitungan kadar Lunacridine pada ekstrak kayu sanrego (L. amara Blanco) dengan Metode KLT-Densitometri

\begin{tabular}{ccccc}
\hline Sampel & Rf & $\begin{array}{c}\text { Luas } \\
\text { Area }\end{array}$ & $\begin{array}{c}\text { Kadar lunacridine } \\
\text { dalam sampel }(\mu \mathrm{g})\end{array}$ & $\begin{array}{c}\text { Kadar rata-rata lunacridine } \\
\text { dalam sampel }(\mu \mathrm{g} / \mu \mathrm{L})\end{array}$ \\
\hline $\begin{array}{c}\text { Maserasi } \\
1\end{array}$ & - & - & - & \\
2 & 0,22 & 2628,22 & 35,10 & 35,03 \\
3 & 0,22 & 2621,59 & 34,97 & 37,52 \\
\hline Refluks & & & & \\
1 & 0,22 & 2812,08 & 38,75 & \\
3 & 0,22 & 2644,13 & 35,42 & \\
\hline
\end{tabular}

Keterangan : (-) not available (Tidak sesuai)

\section{PEMBAHASAN}

Kayu sanrego (L. amara Blanco) digunakan sebagai tanaman obat tradisional, dari beberapa pengalaman kayu sanrego (L. amara Blanco) dapat mengobati bengkak, antikanker, gastralgia dan bagi penduduk Sulawesi Selatan khususnya Kabupaten Bone digunakan sebagai obat aprodiksia. Senyawa pada Sanrego yang dapat sebagai antikanker adalah lunacridine. Lunacridine merupakan golongan alkaloid kuinolin, dimana alkaloid sendiri bersifat basa dan memiliki 1 atom nitrogen. Alkaloid kuinolin mempunyai 2 cincin karbon dengan 1 atom nitrogen. Penggunaan dua metode ekstraksi bertujuan untuk mengetahui pengaruh metode ekstraksi terhadap ekstrak yang diperoleh, noda pada profil KLT dan penentuan kadar lunacridine dengan menggunakan KLT-Densitometri.

$$
\text { Densitometri merupakan }
$$

metode analisis instrumental berdasarkan pada interaksi radiasi elektromagnetik dengan analit yang merupakan bercak pada KLT. Densitometri lebih dititik beratkan untuk analisis kuantitatif analit-analit dengan kadar kecil, yang mana diperlukan pemisahan terlebih dahulu dengan KLT. Pada KLT-Densitometri yang terukur adalah nilai Rf, panjang gelombang maksimum lunacridine 303 $\mathrm{nm}$, luas area dan kadar sampel. Kelebihan dari densitometri ini yaitu cepat, lebih murah, mudah digunakan dan memiliki kepekaan tinggi dalam menganalisis senyawa yang akan dideteksi, karena kepekaan alat yang sangat tinggi maka diperhatikan cara penotolan dan volume yang ditotolkan 
Penentuan kadar lunacridine pada ekstrak Kayu Sanrego (Lunasia amara Blanco) yang diekstraksi dengan metode Maserasi dan Refluks.

harus seragam agar diperoleh hasil yang baik.

Metode ekstraksi dalam penelitian ini adalah maserasi dan refluks. Dimana maserasi mewakili metode ekstraksi secara dingin sedangkan refluks mewakili metode ekstraksi secara panas. Untuk masingmasing metode digunakan cairan penyari yang sama yaitu metanol. Metanol merupakan pelarut semi polar dimana pelarut ini dapat menyari komponen-komponen kimia yang bersifat polar dan non polar.

Sampel ditimbang sebanyak 150 gram untuk masing-masing metode ekstraksi (maserasi dan refluks) maka diperoleh ekstrak kental dari metode maserasi yaitu 3,67 gram dan metode refluks 5,27 gram. JumLah ekstrak yang diperoleh pada metode refluks lebih banyak dibandingkan dengan metode maserasi disebabkan karena metode ini digunakan untuk simplisia yang mempunyai tekstur keras seperti batang, akar, dan biji sehingga memungkinkan zat yang tersari lebih banyak.

Setelah diperoleh ekstrak maka dilakukan uji pendahuluan terhadap dua metode ekstraksi tersebut, dimana identifikasi lunacridine dilakukan dengan KLT yaitu noda ekstrak yang ada pada lempeng KLT yang telah di elusi dengan $n$-heksan : etil asetat (2 : 8) keduanya sejajar, berwarna ungu pada lampu UV $254 \mathrm{~nm}$ dan nilai $\mathrm{Rf}$ sama dengan pembanding lunacridine. Ini menunjukan bahwa ekstrak tersebut positif mengandung lunacridine.

Pengujian dilanjutkan dengan membuat larutan baku lunacridine, larutan dibuat empat konsentrasi masing-masing 20 ppm, 40 ppm, 60 ppm dan 80 ppm. Sampel dan pembanding lunacridine masingmasing ditotolkan pada lempeng KLT. Selanjutnya dilakukan analisis menggunakan KLT-Densitometri dengan panjang gelombang maksimum $303 \mathrm{~nm}$. Dari analisis menggunakan KLT-Densitometri diperoleh kadar lunacridine pada metode refluks ekstrak kayu sanrego (L. amara Blanco) sebanyak 37,52 $\mu \mathrm{g} / \mu \mathrm{L}$ dan maserasi 35,03 $\mu \mathrm{g} / \mu \mathrm{L}$. Ini menunjukan bahwa kadar lunacridine pada metode refluks yang paling sesuai menyari lunacridine dari pada metode maserasi.

\section{KESIMPULAN}

Dari hasil penelitian yang telah dilakukan dapat disimpulkan bahwa metode yang paling sesuai untuk menyari lunacridine pada kayu sanrego (L. amara Blanco) adalah 
Penentuan kadar lunacridine pada ekstrak Kayu Sanrego (Lunasia amara Blanco) yang diekstraksi dengan metode Maserasi dan Refluks.

refluks dengan kadar $37,52 \mu \mathrm{g} / \mu \mathrm{L}$

dibandingkan maserasi $35,03 \mu \mathrm{g} / \mu \mathrm{L}$

berdasarkan parameter profil KLT-

Densitometri dengan menggunakan cairan penyari metanol.

\section{DAFTAR PUSTAKA}

1. Nadjeeb. Penggunaan obat tradisional (Online). http://nadjeeb.wordpress.com/2010 /02/23/penggunaan-obat- tradisional/, diakses tanggal 23 Oktober 2010.

2. De PL, Lugot $G$, Pancho S. Handbook On Philipine Medical Plant Volume II. Los Banos : University Of Philipine, 1978.

3. Goodwin S. Smith AF, Velasquez AA, Horning EC. Alkaloids Of Lunasia amara Blanco Isolasi Studies. J Am Chem Soc 1959. 